\title{
A CONCEPÇÃO PÓS-POSITIVISTA DO PRINCÍPIO DA LEGALIDADE
}

\author{
ALEXANDRE SANTOS DE ARAGĀO*
}

Preliminarmente, devemos destacar que pouca divergência há quanto à necessidade de base legal para a Administração Pública editar os seus atos concretos e normativos. As discussões se centram, contudo, muito mais do que sobre o cabimento desta ou daquela espécie de regulamento, no nível de densidade normativa das quais estas leis devem se revestir para outorgar poderes à Administração; ou seja, até que ponto a lei deve preestabelecer os conteúdos dos atos a serem expedidos infra-legalmente pela Administração Pública; até que ponto pode conferir liberdade à Administração Pública para definir direitos e obrigações.

Charles EISENMANN ${ }^{\prime}$ enumera quatro possíveis visões do Princípio da Legalidade, ou seja, quatro possíveis formas de se conceber a subordinação da Administração à lei. Vejamos, uma a uma, das menos para as mais restritivas dos poderes da Administração Pública:

1. Para a atuação da Administração Pública é suficiente que ela não viole qualquer norma legal, ou seja, na inexistência de normas legais que a obrigue a fazer ou a deixar de fazer algo, tem liberdade para atuar. Nesta acepção, a legalidade seria uma relação de não-contrariedade com a lei. ${ }^{2}$

2. A Administração Pública pode fazer o que uma norma superior, legal ou constitucional, a autorize, a habilite a fazer, ainda que não entre nos detalhes do conteúdo dos atos a serem emitidos. Nesta perspectiva, a Administração não possui liberdade na ausência de lei, mas basta que esta lhe atribua a

1 EISENMANN, Charles. Cours de Droit Administratif, Tomo I, Ed. L.G.D.J., Paris, 1982, pp. 462 a 472.

2 EISENMANN, Charles. O Direito Administrativo e o Princípio da Legalidade, in Revista de Direito Administrativo, vol. 56, pp. 54/5. 
competência. Privilegia-se, portanto, a existência de habilitação formal para o exercício de competência para a realização de determinados fins.

3. A Administração só pode emitir os atos que se esteiem em norma legal, não apenas habilitadora, mas predeterminante do conteúdo dos atos a serem praticados.

4. Em um plus em relação à visão anterior, a Administração Pública tem que estar apoiada em norma legal que esgote o conteúdo dos atos a serem tomados, que também deve determinar (não apenas facultar) a sua prática. Por esta visão, todas as competências da Administração Pública só poderiam ser vinculadas.

A primeira visão é inviável por igualar a liberdade de atuação da Administração Pública àquela dos indivíduos, e, no choque entre estas duas liberdades, a esfera de autonomia dos indivíduos se veria, em razão da imperatividade dos atos da Administração Pública, reduzida a limites aquém daqueles que devem decorrer do Estado de Direito - que resguarda os indivíduos contra a vontade unilateral das autoridades administrativas.

A quarta também seria inviável, mas por razões opostas, já que impediria qualquer esfera de apreciação própria da Administração Pública em um Estado social de Direito, que possui múltiplas e complexas atribuições, a serem exercidas em um contexto de grande dinamismo.

A discussão fica, portanto, entre as duas opções intermediárias, que vêem o princípio da legalidade como impositivo de uma relação de conformidade da Administração Pública com a lei.

Pela terceira, a Administração Pública pretensamente não criaria direitos e obrigações, que já estariam previamente estabelecidos pela lei, mas apenas detalharia, ainda que com certa margem de discricionariedade, a maneira com deveriam ser implementados.

Pela segunda concepção, ao revés, bastaria a existência de leis autorizativas da atuação administrativa, que, sem chegar a predeterminar o conteúdo dos direitos e obrigações, facultam à Administração Pública tomar uma entre várias medidas possíveis (ex.: "Tomar todas as medidas necessárias para alcançar os objetivos $\mathrm{x}, \mathrm{y}$ e z").

Odete MEDAUAR, ${ }^{3}$ uma das poucas administrativistas brasileiras que trata da essencial doutrina de EISENMANN, preleciona: "O terceiro significado - somente são permitidos atos cujo conteúdo seja conforme a uma hipótese abstrata fixada explicitamente por norma legislativa —, traduz uma concepção rígida do princípio da legalidade e corresponde à idéia de Administração somente executora da lei; hoje

3 MEDAUAR, Odete. Direito Administrativo Moderno, Ed. RT. $7^{4}$ ediçāo, São Paulo, 2003, p. 137. 
não mais se pode conceber que a Administração tenha só este encargo. ${ }^{4}$ Esse significado do princípio da legalidade não predomina na maioria da atividade administrativa, embora no exercício do poder vinculado possa haver decisões similares a atos concretizadores de hipóteses normativas abstratas. ${ }^{5} \mathrm{O}$ segundo significado exprime a exigência de que a Administração tenha habilitação legal para adotar atos e medidas; desse modo, a Administração poderá justificar cada uma de suas decisões por uma disposição legal; exige-se base legal no exercício dos seus poderes. Esta é a fórmula mais consentânea à maior parte das atividades da Administração brasileira, prevalecendo de modo geral. No entanto, o significado contém gradições; a habilitação legal, por vezes, é somente norma de competênciit, isto é. norma que atribui poderes para adotar determinadas medidas. ficando a autoridade com certa margem de escolha no tocante à substância da medida; por vezes, a base legal expressa um vínculo estrito do conteúdo do ato ao conteúdo da norma ou às hipóteses aí arroladas."

Tomando por paradigma as quatro possíveis concepções da legalidade colacionadas por EINSENMANN. podemos afirmar que GUIDO ZANOBINI ${ }^{6}$ critica a visão de que a Administração Pública constitui um poder apenas "executivo", já que a ela não compete simplesmente "executar e implementar a norma jurídica, mas sim, o que é profundamente diverso, satisfazer os interesses coletivos"?

4 Em outra obra, a Professora Odete MEDAUAR minudencia à sua posiçāo: "Essia conotą̧ão decorre da idéia da Administraçăo como executora da lei, que predominou no século XIX e princípios do século XX. Hoje essa idéia vemn sendo questionada, ante as atribuiçōes atuais do Poder Executivo e da Administração e sobretudo porque a função administratival talvez nunca tenha se limitado a executar a lei ou a executar a lei de ofício. Embora norteada pelo Princípio da Legalidade, a função administraiva não tem o fïn único de executar a lei, desempenhando amplo rol de atividades que propiciam serviços, bens, utilidades, dificilmente 'enquadráveis' na rubrica 'execução da lei"' (MEDAUAR, Odete. A Processualidade no Dircito Administrativo. Ed. RT. São Paulo, 1993, p. 53)

5 "A segurança jurídica da previsibilidade aplicativa das normas, permitindo almejar como ideal de sistema administrativo uma postura decisória siolgístico-subsuntivat das normas, encontra-se hoje completamente ultrapassada pela flexibilidade do conteúdo da legalidade". (...) Em vez disso, assiste-se a uma progressiva indeterminaçăo e abertura densificadora da normatividade a favor da Administração Pública que, por sua esta via, adquire um crescente ativismo na revelaçăo e construção das soluções concretas e regulamentares, conferindo-se uma inerente maleabilidade à legalidade administrativa que vive tempos de erosão do seu habitual e repetido papel puramente vinculativo da atuação administrativa. (...) Os alicerces políticos do princípio da legalidade administrativa revelam que, ao invés da interpretação tradicional dos postulados filosóficos liberais, a vontade do poder executivo nunci é totalmente alheia ao conteúdo configurativo dessa mesma legalidade: a idéia de uma genérica natureza heterovinculativa da legalidade face ao poder executivo é um mito" (OTERO, Paulo. Legalidade e Administração Pública - o sentido da vinculą̧ão administrativa à juridicidade, Ed. Almedina. Coimbra, 2003, pp. 162, 894 e 1.101, grifamos).

6 ZANOBINI, Guido. L'Attività Amministrativa e la Legge, in Scritti Vari di Diritto Pubblico. Ed. Giuffrè, Milano, 1955, pp. 203 a 218.

7 "Para Hegel, a função do Monarca na aplicação da lei seria somente a de por o pingo no " $i$ ". "Todavia, em todos os filósofos não se contesta a questão de como se deve preencher o abismo entre a lei necessariamente geral, que deve 'dominar', e as necessárias decisōes nas situações 
Também critica a que seria a primeira acepção referida por EINSENMANN, que para ele peca pelo excesso da reação contra a visão meramente executiva da Administração Pública. Para Guido ZANOBINI não se pode conceber que a Administração Pública, a exemplo dos particulares, possa fazer tudo o que não esteja vedado em lei, já que para eles a lei é uma vontade exógena, ao passo que para a Administração é uma vontade interna ao Estado do qual faz parte, o que geraria uma iniqüidade na relação entre os particulares e a Administração Pública/Estado, sujeitando aqueles totalmente à vontade desta.

Para os particulares, afirma ZANOBINI, como a lei a eles é externa, se deve, em respeito às suas liberdades, permitir tudo o que por elas não é mediata ou imediatamente restringido. Já a Administração, sendo o próprio Estado na persecução dos seus fins, só pode fazer o que a lei permite, seja vinculada ou discricionariamente: a lei - o próprio Estado - pode determinar à Administração tanto os fins a serem alcançados e também os meios para persegui-los, como pode estabelecer apenas aqueles, deixando para a Administração - não mera executora - a escolha dos meios. ${ }^{8}$

É nesta perspectiva que Guido ZANOBINI afirma, em expressão tão citada pela doutrina brasileira, às vezes sem a citação da fonte e sem o aprofundamento que ela demanda, que "o indivíduo pode fazer tudo o que não the é expressamente vetado, ao passo que a Administração pode fazer apenas o que a lei expressamente the consente." 9

José Manuel SÉRVULO CORREIA ${ }^{10}$ deduz da distinção de Charles EISENMANN as seguintes concepções do Princípio da Legalidade: (a) não-contrariedade (compatibilidade, preferência da lei ou legalidade-limite), ou seja, a exigência de a ação administrativa não poder entrar em contradição com uma lei, apesar de não necessariamente haver de nela ter um esteio; e (b) conformidade (reserva de lei ou legalidade-fundamento), que, além da não-contradição, exige que a Administração

concretas. Não se pode desconhecer que se trata de algo mais do que uma simples aplicação da lei. Trata-se do estabelecimento de normas sob o Direito Constitucional e de atos relacionados com uma situação concreta. Ambas coisas exigem que sejam adotadas decisões obrigatórias para outros. Assim, com a simples fórmula de que não devem ser os homens que dominam, mas sim as leis abstratas e impessoais, não se resolveu nada" (LARENZ, Karl. Derecho Justo, trad. Luís Diez-Picazo, Ed. Civitas, Madrid, 1985, pp. 153/4). Vê-se, assim, o caráter meramente mítico de uma estrita vinculação da Administração Pública à lei.

8 ZANOBINI, Guido. L'Anività Amministrativa e la Legge, in Scritti Vari di Diritto Pubblico, Ed. Giuffrè. Milano, 1955, p. 215.

9 ZANOBINI, Guido. L'Altività Amministrativa e la Legge. in Scritti Vari di Diritto Pubblico, Ed. Giuffrè, Milano, 1955, pp. 206/7. É nesta esteira que afirma que toda atuação da Administração Pública é sempre relevante para o Direito, já que é sempre desenvolvida com base em alguma habilitação legal, o que é de grande importância para a afirmação do controle jurisdicional de todos os atos da Administração Pública, inclusive dos discricionários, em que a Administração possui certa margem de apreciação.

10 CORREIA, José Manuel Sérvulo. Legalidade e Autonomia Contratual nos Contratos Administrativos, Livraria Almedina, Coimbra, 1987, pp. 58-63 e 309-312. 
atue com respaldo em alguma lei, de forma que os seus atos sempre consistam de alguma forma na aplicação de preceitos legais (ou, naturalmente, constitucionais).

Esta "conformidade" subdivide-se, podendo reduzir-se à (b. I) mera legalidade formal, pela qual "basta a existência de normas que tenham por objectivo regular a produção jurídica do acto, atribuindo poderes para a sua emissão", não sendo necessária a (b.2) legalidade material, por força da qual a lei já predetermina parte ou todo o conteúdo dos atos a serem praticados pela Administração Pública."

Entre nós, FERNANDO VERNALHA GUIMARÃES ${ }^{22}$ aborda a matéria com maestria: "A partir de um núcleo mínimo e irredutível de densidade normativo-legal, a variação de intensificação que exsurge quanto à densidade de normação jurídica de conformação acaba por implicar o surgimento de um rol quase interminável de feições da legalidade de conformação.

Na classe das relações de conformidade é possível - na esteira de terminologia proposta por Lorenza CARLASSARE, adotada por Ruy MANCHETE e SÉRVULO CORREIA - estabelecer uma dicotomia entre legalidade formal e legalidade substancial ou material, referindo a primeira como a fixação de uma base mínima de legalidade para o exercício de atividade administrativa, consistente na regulação normativo-legal da produção jurídica do ato, na atribuição de poderes para sua emissão. Alude a legalidade substancial à exigência de estatuição normativa do conteúdo do ato; Se, no âmbito da conformidade formal, a norma jurídica habilitante se esgota em fornecer uma conformação da produção jurídica do ato, na conformação material, o estatuto normativo, ao conformar a disciplina própria do ato, assim o fará segundo uma graduação específica de conformação. cujo grau de conformação variará conforme a 'densidade-abertura'."

Todavia, se deve advertir que a legalidade formal jamais vai ser apenas formal, já que a lei habilitadora da Administração Pública ou, em última hipótese, até mesmo o ordenamento jurídico em seu conjunto, sempre condicionarão de alguma maneira o conteúdo dos atos a serem emitidos pela Administração Pública. ${ }^{13}$

11 CORREIA, José Manuel Sérvulo. Legalidade e Autonomia Contratual nos Contratos Administrativos, Livraria Almedina, Coimbra, 1987, pp. 58 a 60. Também analisando a nomenclatura de Charles EISENMANN, Juan Igartua SALAVERRÍA observa que a compatibilidade e a conformidade são distintas porque o significado desta é o de deduzibilidade (não apenas compatibilidade) da lei (SALAVERRÍA, Juan Igartua. Princípio de Legalidad, Conceptos Indeterminados y Discrecionalidad Administrativa, in Revista Española de Derecho Administrativo - REDA, 1996, vol. 92, versão CD-ROM). Todavia, segundo o autor, esta deduzibilidade poderia advir de dois momentos argumentativos diferentes: com a lei prevendo a hipótese de incidência e a consequèencia jurídica que deve se seguir à sua realização concreta; ou com a lei prevendo fins e meios para alcançá-los (silogismo prático). No primeiro caso, da lei só pode advir uma alternativa para a Administração Pública, ao passo que no segundo, caso haja mais de um meio possível para alcançar o fìm, há opçōes para o aplicador da lei, eclodindo. assim, o que costumamos chamar de discricionariedade administrativa.

12 GUIMARÃES, Fernando Vernalha. Alteração Unilateral do Contrato Administrativo, Ed. MaIheiros, São Paulo, 2003, p. 250.

13 CORREIA, José Manuel Sérvulo. Legalidade e Autonomia Contratual nos Contratos Administrativos, Livraria Almedina, Coimbra, 1987. pp. 311 e 312. 
CHARLES EISENMANN, com cuja opinião anuímos, sustenta que não há como ser aplicado o critério da legalidade substancial em uma versão extrema (de máxima densidade normativa das leis) porque pressupõe que apenas a lei cria direitos e obrigações, esquecendo que, na verdade, todo e qualquer regulamento possuirá em determinada medida, sob pena da sua inutilidade, algum papel criativo em relação à lei; posição que é contestada por José Manuel SÉRVULO CORREIA, para quem a assertiva levaria ao fïm da diferença entre regulamentos de execução e independentes, já que inexistiriam aqueles. Para José Manuel SÉRVULO CORREIA o regulamento de execução é, então, aquele que, ainda que com alguma possibilidade criativa, tem uma relação de derivação lógica da lei, propiciando que a lei seja aplicada de forma segura e uniforme. ${ }^{14}$

Devemos, ao analisar a Legalidade Administrativa, nos desvestir de uma série de mitos oitocentistas, até porque, apesar de a idéia de liberdade dos revolucionários franceses ser fortemente ancorada na legalidade. logo após a Revolução Francesa vigia apenas a legalidade em seu aspecto de mera não-contrariedade, idéia que começou a ser combatida por não estar de acordo com o Estado de Direito. ${ }^{15}$

Partindo-se da pirâmide normativa de KELSEN, constatamos, por um lado, que todo ato da Administração Pública está apoiado em um ato superior — geralmente uma lei -, mas também que, por outro lado, "toda concrę̧ão de normas gerais, toda passagem de um grau superior para um grau inferior da ordem jurídica, implica preencher um vazio, respeitando os limites traçados pelas normas de grau superior. Como a concref̧ão das disposições inferiores nunca pode ser completamente prevista pela norma superior, existe um espaço criativo, que, conforme a postura kelseniana, pode e deve ser integrada não só pelo administrador público, como também pelo juiz. Considera que ambas as funções não estão completamente determinadas pela legislação, já que existe uma margen mais ou menos ampla de apreciação, mas esta liberdade não é nunca absoluta e, ao contrário, sempre pressupõe uma norma prévia". ${ }^{16}$

É por isto que entendemos que todo o regulamento é, simultaneamente, em maior ou em menor grau, executivo e criativo. Com efeito, como adverte Carlo SALTELLI, "mesmo os regulamentos independentes não têm fundamento distinto daquele dos outros regulamentos, (...) vez que servem, como os outros regulamentos,

14 CORREIA, José Manuel Sérvulo. Legalidade e Autonomia Contratual nos Contratos Administrativos, Livraria Almedina, Coimbra, 1987, pp. 60 e 61. Alguns autores equivalem a legalidade formal à reserva relativa $\mathrm{e}$ legalidade material à reserva absoluta, mas na verdade as duas espécies de reserva se encontram no âmbito da legalidade material, sendo relativa quando o conteúdo estiver apenas parcialmente predefinido, e absoluta quando a lei descrever na íntegra os atos a serem emitidos pela Administraçāo Pública.

15 SESÍN, Domingo J. Administración Pública. Actividad Reglada. Discrecional e Técnica. Ed. Depalma, Buenos Aires. 1994. pp. 1-11.

16 SESÍN, Domingo J. Adminisıración Püblica. Actividad Reglada, Discrecional e Técnica, Ed. Depalma, Buenos Aires, 1994, pp. 04 e 05, grifamos. Assim, demonstrada fica a inviabilidade de se adotar uma visão rígida da legalidade, pela qual a Administração Pública só poderia fazer aquilo que a lei previamente a autorize. em outras palavras, não há como a lei predeterminar todos os elementos dos atos administrativos, o que, na prática, nunca foi na prática possível ao Legislador. 
à execução de uma lei: particularmente daquelas leis que atribuem à Administração um determinado poder, mesmo que sem discipliná-lo sequer em suas linhas gerais. Nos regulamentos de execução, a maior parte das normas concernentes a uma determinada matéria já se encontra disciplinada na lei, de maneira que o regulamento não tem outra finalidade além de acrescentar novas disposições, e a matéria permanece regulada principalmente pela lei e subsidiariamente pelo regulamento; nos regulamentos independentes, ao revés, a parte principal da disciplina da matéria é assumida pelo regulamento dada a exiguidade da norma legislativa". ${ }^{17}$

A grande questão da matéria do poder regulamentar da Administração Pública não é propriamente a de se determinar a sua extensão deste, mas sim definir qual é a densidade normativa mínima que a sua base legal deve ter para que seja consentânea com o Estado Democrático de Direito e com a natureza subordinada do poder regulamentar.

Equívocos na identificação do ponto essencial das divergências são facilmente notados quando são tecidas críticas aos regulamentos que são oriundos de atribuições em termos largos de poderes normativos à Administração Pública, o que, segundo afirmam, gerariam inconstitucionais regulamentos autônomos ou delegações de poderes legislativos. Mas estas críticas são dirigidas na maioria das vezes diretamente aos regulamentos, não à sua base normativa. Ora, se o regulamento é inconstitucional é porque o teria sido, outrossim, a lei que atribuíra poderes demasiadamente amplos à Administração Pública. E mais, se olvida que atacar o regulamento, mantendo a atribuição de poderes normativos, gerará situações de desigualdade, uma vez que o regulamento homogeneíza o comportamento discricionário dos diversos agentes da Administração Pública. Em outras palavras, mesmo na perspectiva destes autores mais tradicionalistas, caso se mantenha a lei de conteúdo aberto, mas se vede à Administração a edição de normas gerais e abstratas, os seus agentes aplicarão a lei com imensa liberdade, caso a caso, o que só acarretará maior diferenças de tratamento e insegurança entre os cidadãos. ${ }^{18 .} 19$

17 SALTELLI, Carlo. Potere Esecutivo e Norme Giuridiche, Mantellate, Roma, 1926. pp. 103/4.

18 Integramos, assim, a corrente liderada por GNEIST, CAMMEO, SANTI ROMANO e RANELLETTI, para os quais " poder regulamentar teriam os órgãos da Administração Pública na medida em que a lei lhes atribuísse poder discricionário para a prossecuçĩo em concreto de determinados interesses públicos. Esses órgãos poderiam dispor por via geral e abstraia (por via regulamentar. em suma) quando a lei lhes houver atribuído a faculdade de proceder discricionariamente, com actos individuais e concretos, dentro dos limites legais. Quem possui fuculdades discricionárias, segundo tal doutrina, tem faculdades regulamentares: a Administraçĩo poderia auto-vincular a sua competência discricionária e proceder, daí em diante, não de acordo com a sua apreciação de cada caso concreto, com as exigências do seu conhecimento específico, mas sim de harmonia com as normas que precedentemente a si própria se houvesse fixado" (cf. QUEIRÓ. Afonso. Teoria dos Regulamentos, in Revista de Direito e de Estudos Sociais, Livraria Almedina, Coimbra, janmar/1986, pp. 09 e 10).

19 Para uma análise das vantagens da discricionariedade ser exercida através de atos regulamentares, principalmente para a segurança jurídica e previsibilidade das ações dos administrados, ver BASSI, Nicola, Princípio di Legalià ‘' Poteri Amministrativi Impliciti, Giuftrè Edịore. Milano. 2001, pp. 283/4. 
De nossa parte, a lei não precisa preestabelecer os elementos das relações jurídicas a serem formadas, ou, em outras palavras, não é necessário que ela tenha que chegar a fixar os direitos e obrigações, que teriam, segundo afirma a doutrina mais tradicional-liberal, apenas a forma do seu mero exercício definida pelos regulamentos de "mera" execução. ${ }^{20}$ Integramos a corrente daqueles para quem basta a habilitação legal dos poderes da Administração Pública, sem que a lei precise entrar na matéria, a ser regulada pela Administração Pública. Há entre a lei e o regulamento uma relação de "heterointegração" entre a lei e os regulamentos dela decorrentes, com importantes reflexos inclusive " no plano da interpretação das fontes, considerando a função integradora conferida pela lei às fontes secundárias na disciplina das relações econômicas".?1

Não seria suficiente, contudo, apenas a previsão legal da competência da Administração Pública editar normas sobre determinado assunto. Mister se faz que a lei estabeleça também princípios, fïnalidades, políticas públicas ou standards 22 que propiciem o controle do regulamento (intelligible principles doctrine), já que a atribuição de poder normativo sem que se estabeleçam alguns parâmetros para o seu exercício não se coadunaria com o Estado Democrático de Direito, que pressupõe a possibilidade de controle de todos os atos estatais.

Apesar de não encampá-la explicitamente, Luís Roberto BARROSO vê, com efeito, a "tendência" em se admitir que o Legislador conceda amplos poderes normativos à Administração Pública, desde que " ofereça parâmetros adequados e suficientes para a atuação normativa". 23

20 Para um entendimento mais tradicional do Princípio da Legalidade, limitando os regulamentos administrativos apenals àqueles que seriam de "mera execução", o que, au nosso ver, é de existência impossível, ver o indispensável texto de DI PIETRO, Maria Sylvia Zanella. Limites da Funçāo Reguladora das Agências diante do Princípio da Legalidade, in Direito Regulatório (coord. Maria Sylvia Zanella Di Pietro), Ed. Fórum, Belo Horizonte, 2003, pp. 27 a 60.

21 COCOZZA, Francesco. Profili di Diritto Costituzionale applicato all'Edconomia, Volume I (Incidenza dei Rapporti Economici sull'Organizzazione del Potere Político e sul Sistema dele Fonti del Diritto), G. Giappichelli Editore, Torino, 1999, p. 177.

22 "O standard jurídico constitui uma maneira de solução de conflitos de interesses na qual o aplicador da lei adota diretivas como normas de conduta, que the permitem resolver o caso com sentido de justiça considerando os fatores econômicos, sociais e até mesmo morais existentes dentro da norma legal e de princípios de aplicação flexível. Há nele uma boa dose de empirismo e pragmatismo. A equidade quase sempre está neste tipo de decisĩo. e a eficiência será maior quanto maior for a flexibilidade institucional" (BIELSA. Rafial. Metodologia Juridica, Libreria y Editorial Castellví, Santa Fé, 1961, pp. 509 e 510). Como observa Francesco MANGANARO, "não se trata de desvalorizar o papel da lei, mas de reconsiderar a sua função $\mathrm{cm}$ um ordenamento pluralista. Se a rápida evolução social já era um motivo para preferir uma legislação farta de princípios e standards, por mais fortes razões, um ordenamento $\mathrm{cm}$ que há um efetivo pluralismo requer uma formulação legislativa de tal gênero (MANGANARO. Francesco. Principio di Legalità e Semplificazione dell Attività Amministrativa: i profili critici e principi ricostruthivi, Edizioni Scientifiche Italiane, Napoli. 2000, p. 171).

23 BARROSO, Luís Roberto. Apontamentos sobre o Princípio da Legalidade (Delegaçôes legislativas, poder regulamentar e repartição constinucional das competências legislativas), in Temas de Direito Constitucional. Ed. Renovar, Rio de Janeiro, 200 I. p. 187. Esta tendência é verificada 
Note-se que nos Estados Unidos da América do Norte, onde também havia forte setor doutrinário e jurisprudencial no sentido de que as leis com tal (baixa) densidade normativa seriam inconstitucionais por constituírem delegações de poderes legislativos, a Suprema Corte, apesar de ainda haver reaçôes de alguns autores e de algumas Cortes estaduais, acabou se firmando, como expõe John H. REESE, no sentido de que "o que é proibido é a transferência de poderes ilimitados. Normalmente, tal transferência limitada advém da linguagem utilizada na lei autorizando a Administração a editar normas apropriadas para cumprir as finalidades assinaladas na lei. A transferência de poderes normativos também pode estar implícita na linguagem legislativa, ainda que não haja atribuição normativa expressa". ${ }^{24}$ William F. FUNK explica: "o Congresso legisla e a Administração executa as leis; para que a Administração execute as leis, estas leis devem conter um princípio claro (intelligible principle) para guiar a Administração, já que, do contrário, a Administração estaria legislando por conta própria". ${ }^{25}$

Recentemente, a Suprema Corte teve a oportunidade de reafirmar a sua posição no caso Whitman v. American Trucking Associations Inc.. em que, apesar da posição adotada pelo Tribunal Federal ad quem pela inconstitucionalidade da lei atributiva de largos poderes normativos a agência administrativa, considerou constitucional disposição legal que atribuiu poder normativo para "estabelecer padrões de qualidade do ar, cuja observância seja necessária para proteger a saúde pública".

A Corte Federal recorrida havia decidido que a lei não continha um "inteiligible principle" porque dela não se poderiam deduzir as quantidades de poluentes que seriam aceitáveis. A Suprema Corte, contudo, entendeu, com base em diversos precedentes análogos, que do termo "saúde pública" decorria um princípio suficientemente claro ("'public health' provided a sufficiently intelligible principle"). ${ }^{26}$

Também na Itália se exige que a lei atributiva do poder regulamentar contenha os respectivos "princípios e critérios diretivos" 27; ao passo que na Alemanha "o

até mesmo no Dircito Privado, vejamos: "Propugna-se, na doutrina, o estabelecimento de uma codificação estruturada em princípios, standards ou mesmo por cláusulas gerais. Defende-se a adoção de um sistema aberto ou móvel (...). É certo que esta orientução outorga ao juiz uma função bem mais relevante que a visão clássica lhe atribui. Passa ele a poder preencher a norma, dando-lhe maior concreção" (ANDRDADE, Fábio Siebeneichler de. Da Cudificaçāo: crônica de um conceito. Ed. Livraria do Advogado, Porte Alegre, 1997, pp. 156/7).

24 REESE, John H. Administrative Law - Principles and Practice, Westpublishing Co., Saint Paul, Minnesota, 1995, p. 53, grifo do autor.

25 FUNK, William F. Administrative Practice \& Procedure, $2^{4}$ edição, West Grolp, 2001 , p. 522.

26 Isto não quer dizer que a Suprema Corte sempre acate a atribuição legislativa de poderes normativos. Nos casos Panama Refining Co. 1. Ryan e no Schechter Poultry Corp. v. United States a Suprema Corte considerou a atribuição de poderes regulamentares inconstitucional, respectivamente, por não haver limitações à discreção presidencial e por conferir uma "discricionariedade sem limites".

27 ROMANO, Alberto. Relazione di Sintesi, in Amministrazione e Legalità - Fonti Normativi e Ordinamenti (Atti del Convegno, Macerata. 21 e 22 maggio 1999), Giufrè Editore, Milano. 2000, p. 105 . 
Tribunal Constitucional Federal, conjuntamente com a doutrina, criou a figura da Bestimmheitsgebot, ou seja, a exigência de uma determinabilidade, que a lei autorizativa do poder regulamentar deve satisfazer para evitar leis excessivamente genéricas ou que transfiram ao Executivo uma competência normativa sem limites do ponto de vista finalístico (uma "carta-branca"), sendo que, atualmente, a doutrina é cada vez mais propensa a entender suficiente que o 'escopo' possa ser inferido também da interpretação do contexto jurídico no qual a lei de autorização é emanada". 28

Sob o mesmo prisma, se afirma também na doutrina nacional ${ }^{29}$ que o que não pode ocorrer é "'a disciplina normativa produzida pela lei ser tão sumária que sua complementação possa conduzir a um resultado qualquer. Preocupada com a proliferação de leis de baixíssima densidade normativa, a doutrina construiu o conceito de conteúdo essencial (contenu essentiel, wesentlichkeitstheorie). Tais leis devem expressar, na lição de GARCÍA DE ENTERRÍA, uma diretiva legislativa precisa, sem supor uma cessão formal ou em branco de poder normativo'..

A nossa posição é a de que, inclusive à luz do art. 84, IV, CF. os regulamentos editados com base em habitações genéricas de poder normativo poderiam ser considerados regulamentos autônomos, já que, apesar de (como qualquer ato jurídico, em certa escala) criarem direito, também são regulamentos de execução, in casu de execução da habitação legal e dos standards genéricos que a condicionam. É claro que a definição de que standards propiciam o controle não é uma questão fácil, que só pode ser dirimida em relação a cada habitação legal específica, no conjunto da lei na qual está contida e. até mesmo, no conjunto do ordenamento jurídico.

No mesmo sentido propugnado, o Superior Tribunal de Justiça - $\mathrm{STJ}^{30}$ lavrou acórdão no qual o Ministro Humberto Gomes de Barros afirmou a possibilidade da Administração Pública, para alcançar as finalidades genéricas da disciplina da matéria, mas sem qualquer autorização legal específica, restringir a liberdade dos "postos de gasolina" adquirirem combustíveis. A importância do acórdão é que é un dos poucos exemplos em que a nossa jurisprudência foi além de questões atinentes ao caso concreto, tratando do âmago doutrinário e teórico da matéria, ou seja, do que deve ser entendido como "execução de lei". Vejamos:

*A Constituição Federal, em seu art. 170, preceitua que a ordem econômica é fundiuda na valorização do trabalho humano e na livre iniciativa, tendo por finalidade assegurar a todos a existência digna, conforme os princípios que enuncia. No seu art. 174 pontifica que, como agente normativo, e regulador da atividade econômica, o Estado exercerá, na forma da lei, as funções de

28 ROMANO. Marria Chiara. Princípio di Legalità e Regolamenti in Germania, in Amministrazione e Legalitì - Fonti Normativi e Ordinamenti (Alti del Convegno. Macerata. 21 e 22 maggio 1999), Guffre Editore. Milano. 2000, p. 220

29 PESSOA. Robertônio Sinnos. Ailmimistrą̧ão e Reghtaçäo. Ed. Forense, Rio de Janeiro, 2003. p. 145.

30 MS 4.578 DF (grifos nossos;. 
fiscalização, incentivo e planejamento. Desses dispositivos resulta claro que o estado pode atuar como agente regulador das atividades econômicas em geral, sobretudo das que cuidam as empresas que atuam em um setor absolutamente estratégico, daí lhe ser lícito estipular preços que devem ser por elas praticados. Montado nestes argumentos, não tenho dúvida em afirmar que o senhor Ministro dispõe de autoridade para impedir que o granelista venda combustível ao varejista ligado a bandeira que não é a sua. Como registrei acima, controlar à execução de determinada norma é fazer com que ela se desenvolva em busca dos fins sociais para a qual a regra foi concebida. Os preceitos que disciplinam a distribuição de combustíveis tem como finalidade fazer com que os usuários de tais produtos recebam, com segurança e facilidade, produtos de boa qualidade. Isto ocorre, porque, a exibição do logotipo de marca famosa traduz a afirmação de que no local se vende daquela marca. Ora, se o posto negocia produtos cuja origem não corresponda à sua bandeira, ele estará enganando o freguês (...). Quando o freguês é iludido, a distribuição de combustível não estará correspondendo aos fins sociais que orientam as normas disciplinadoras da distribuição de combustíveis".

O Supremo Tribunal Federal - STF em diversas ocasiões também já fixou a legitimidade da atribuição de poder normativo através de standards e finalidades genéricas estabelecidas em lei. Em recente decisão liminar em Ação Direta de Inconstitucionalidade (ADIN n ${ }^{\circ}$ 1.668/DF, Relator Ministro Marco Aurélio), o STF considerou constitucional a habilitação normativa efetuada pelos incisos IV e X do art. 19 da Lei Geral de Telecomunicações - LGT em favor da ANATEL, desde que esta subordine-se aos preceitos legais e regulamentares pertinentes. No Recurso Extraordinário n 76.629/RS, o Ministro Aliomar Baleeiro afirmou que "se o legislador quer os fins, concede os meios. (...) Se a L. 4.862 expressamente autorizasse o regulamento a estabelecer condições outras, além das que ela estatuir, aí não seria delegação proibida de atribuições, mas flexibilidade na fixação de standards juridicos de caráter técnico, a que se refere Stati" (grifamos).

Na doutrina nacional, também Miguel REALE observa que "se há algo que caracteriza a Ciência do Direito de nossos dias é a opção pelos modelos jurídicos abertos, os quais deixam amplo campo de decisão a cargo dos juízes e administradores como aplicadores ou aplicadores das leis, por se reconhecer que a complexidade e dinamicidade do mundo contemporâneo não comporta uma legislação cerrada, na qual tudo já se encontre previsto e disciplinado, nem juízes desprovidos de participação criadora". 31

É assim, que, tomando por referência a nomenclatura de José Manuel SÉRVULO CORREIA, não adotamos, nem uma legalidade meramente formal, que não fornece pautas de controle da substância dos atos, nem uma legalidade substancial de excessiva densidade normativa, que exige que a lei estabeleça pelo menos parte

31 REALE, Miguel. Questöes de Direito Público, Ed. Saraiva, 1997, pp. 76/7. 
do conteúdo dos atos a serem expedidos, o que muitas vezes não é compatível com a dinâmica da atividade administrativa, principalmente quando lida com subsistemas sociais de especial desenvolvimento e mutabilidade nos nossos tempos, como a economia e a ciência. ${ }^{32}$

Propugnamos, portanto, por uma superação da separação rígida entre as duas versões extremas de conformidade legal, sustentando que o mínimo de densidade normativa que as leis devem possuir para atribuir poderes à Administração Pública consiste em habilitações normativas calcadas em princípios e valores.

A isto poderiam ser dados vários nomes: legalidade formal axiológica, legalidade material leve ou, o que preferimos, simplesmente legalidade principiológica, no sentido de que as atribuições de poderes pela lei devem, por sucintas que sejam, ser pelo menos conexas com princípios que possibilitem o seu controle; princípios aqui considerados em seu sentido amplo, abrangendo finalidades, políticas públicas, standards, etc. ${ }^{33}$ Trata-se, portanto, de uma visão neo-positivista do Princípio da Legalidade ${ }^{3+}$ resultado de um sistema constitucional tendencialmente principialista. ${ }^{35}$

32 GIANNINI observa que o Princípio da Legalidade $\mathrm{cm}$ sua concepção inicial determinava que todo ato da Administração Pública, em todos seus elementos, devessem estar previstos em lei, mas "esta concepção rígida do princípio da legalidade correspondia à concepção do poder administrativo como poder executivo e, portanto, administração como execução. Já que desta maneira as administrações públicas não teriam como funcionar, foram encontradas duas válvulas, na discricionariedade, e em alguns atos administrativos a serem adotados somente em situações extraordinárias, que eram os regulamentos de necessidade (ordinanze di necessità)"(GIANNINI, Massimo Severo. Diritto Amministrativo, Vol. 1, $3^{3}$ edição, Ed. Giuffrè, Milano, 1993, p. 88).

33 “É preferivel uma legislação de princípios gerais e standards, do que uma legislação feita de regras, cujos conteúdos tendem a ficar obsoletos em um lapso de tempo sempre cada vez mais breve. Em outras palavras, é difícil colocar dentro de normas de conteúdo determinado uma realidade social em contínua evolução. (...) Se sabe que um excesso de regras é o melhor modo de deixar a Administração de se subtrair à sua observância, já que a burocracia, diante de muitus regras, acaba ficando substancialmente livre para aplicar a interpretação que considere mais adequada ao caso concreto. Uma desregulamentação da atividade administrativa não serve para resolver o problema, quando o que se deve é reconsiderar o papel da norma (e do jurista) em um ordenamento em contínua evolução. A consequeiencia imprescindível é a necessidade de "uma revisão do papel constitucional da Administração e do próprio Princípio da legalidade', que a doutrina é chamada a elaborar, em um momento em que já está em fase avançada a transição normativa para uma Administração por objetivos, que exalta o papel da eficiência da ação administrativa" (MANGANARO, Francesco. Principio di Legalità e Semplificazione dell Attività Amministrativa: i profili critici e príncipi rícostruttivi, Edizioni Scientifiche Italiane, Napoli. 2000, p. 165).

34 ALMIRO DO COUTO E SILVA bem coloca o neo-positivismo de uma forma que os valores, então reclamados apenas pêlos jusnaturalistas, são tratados como partes integrantes (e das mais relevantes) do próprio ordenamento jurídico positivo: "Os valores estão dentro do próprio ordenamento jurídico, sob a forma de princípios embutidos na Constituição, de maneira explícita ou implícita. Essa corrente de pensamento, que se alastrou pelo mundo, revigorou os princípios constitucionais já identificados, descobrindo-lhes novos aspectos, e acrescentou ao rol conhecido muitos outros. Os princípios adquiriram, desse modo, no Direito moderno, especialmente o Direito Público, um vigor que nunca tinham possuído, notadamente na configuração da coerência do sistema. As outras normas são sempre a eles necessariamente reconduzidas e são eles que orientam a sua aplicação" (COUTO e SILVA, Almiro. Os Individuos e o Estado na realização de Tarefas 
Com efeito, evoluiu-se para se considerar a Administração Pública vinculada não apenas à lei, mas a todo um bloco de legalidade, que incorpora os valores, princípios e objetivos jurídicos maiores da sociedade, com diversas Constituições (por exemplo, a alemã e a espanhola) passando a submeter a Administração Pública expressamente à "lei e ao Direito", o que também se infere implicitamente da nossa Constituição e expressamente da Lei do Processo Administrativo Federal (art. $2^{\circ}$, Parágrafo único, 1). A esta formulação dá-se o nome de Princípio da Juridicidade ou da legalidade em sentido amplo. ${ }^{36}$

Note-se que esta formulação é uma mão de via dupla: serve tanto para restringir a ação da Administração Pública não apenas pela lei, mas também pelos valores e princípios constitucionais, como para permitir a sua atuação quando, mesmo diante da ausência de lei infra-constitucional específica, os valores da Constituição (lei constitucional) impuserem a sua atuação. ${ }^{37}$

Note-se que o Princípio da Legalidade, do ponto de vista do Direito Privado sofreu idêntica, mas simétrica, evolução: hoje não mais se concebe que, na ausência de lei proibitiva, possa o particular fazer o que quiser, ainda que contrariando valores e princípios constitucionais. A ação do particular é, portanto, diretamente restringida, não só pela lei, como também pelos princípios constitucionais. ${ }^{38}$

Públicas, in Direito Administrativo e Constitucional -- Estudos em Homenagem a Geraldo Ataliba, vol. 2, Ed. Malheiros, São Paulo, 1997, p. 97). Por estas razões, prefirimos o termo "neo" a "pós-positivismo": ainda se trata de positivismo, essencial para a diferenciação do Direito dos demais subsistemas sociais, mas um positivismo calcado em princípios (capazes, o que é essencial, de dialogar com valores meta-jurídicos), não em regras jurídicas. Não estamos, naturalmente, nos referindo à chamada "Escola Neo-positivista" ou da lógica positivista, de Malburgo, do início do século XX, nem, tampouco, adotando o positivismo histórico. Na verdade, estamos realmente mais próximos de alguns dos que passaram a se denominar de "pós-positivistas" (verbi gráta. BARROSO, Luís Roberto. Fundamentos Teóricos e Filosóficos do novo Direito Constitucional Brasileiro: pós-modernidade, teoria crítica e pós-positivismo, in A Nova Interpretação Constitucional, org. Luís Roberto Barroso, Ed. Renovar, Rio de Janeiro, 2003, pp. 1 a 49), apenas crendo que, face à importância dada à positivação de valores meta-jurídicos, poder-se-ia entender como um pouco mais apropriada a denominação de "neo-positivismo". Feita esta observação terminológica, mantemos, contudo, a nomenclatura de "pós-positivismo" por já se encontrar consagrada e por também refletir as idéias que se pretende expressar.

35 OTERO, Paulo. Legalidade e Administração Pública - o sentido da vinculação administrativa à Juridicidade, Ed. Almedina, Coimbra, 2003, p. 168.

36 SESÍN, Domingo J. Administración Pública. Actividad Reglada, Discrecional e Técnica, Ed. Depalma, Buenos Aires, 1994, p. 08.

37 "Estamos diante de um Direito mais dúctil e flexível ante à variedade dos casos, e, portanto, mais justo. Nesta lógica, os conteúdos e não as formas, a compreensão do significado concreto, das tensōes materiais próprias das situações da vida, adquirem força frente à extrema dureza das inflexíveis 'leis', cuja abstração e distância da realidade encastelava o direito no conceitualismo das velhas pandectas de costas para a justiça" (PALOMBELLA, Gianluigi. Filosofia del Derecho Moderna y Contemporânea, Ed. Tecnos, Madrid, 1999, p. 265).

38 "O princípio da legalidade está previsto na Constituição Federal, no artigo $5^{\circ}$, II, que dispõe: 'Ninguém será obrigado a fazer ou deixar de fazer alguma coisa senão em virtude de lei'. O que parece, à primeira vista, ser a mais relevante distinção entre o direito público e o direito privado 
Karl LARENZ adverte que o fato de a lei raramente preestabelecer o conteúdo das decisões concretas a serem tomadas não pode levar à idéia de ausência de vinculação à lei e existência de total liberdade decisória (o fato de a vinculação não poder ser vista de maneira estrita, não quer dizer que não exista qualquer vinculação). Esta vinculação deve, outrossim, ser cumprida com um alcance maior, relacionado com os objetivos e valores visados pela lei e pela Constituição, "através de um processo metodicamente consciente" ${ }^{39}$

$\mathrm{Na}$ verdade deve haver uma relativização da definição de certas competências administrativas como discricionárias ou vinculadas, já que esta definição só pode ser feita em cada caso concreto: o exercício de determinada competência em tese discricionária pode, diante das especificidades de dado caso concreto, determinar à Administração Pública apenas uma atitude juridicamente correta/razoável; e, inversamente, o exercício concreto de determinada competência que em tese é vinculada pode, face às especificidades do caso, gerar diversas atitudes razoáveis/jurídicas que possam ser adotadas pela Administração Pública, e, in extremis, podem até determinar o afastamento da lei naquele caso concreto em razão de a sua aplicação ali e apenas ali, já que do contrário a lei seria inconstitucional - revelar-se contrária aos valores maiores da Constituição e do Direito.

Nesta senda, o Tribunal Supremo Espanhol, se pronunciou no sentido de que "afirmar que a atividade da Administração Pública é vinculada apenas quando o ato está regulado por uma lei ou regulamento, equivale a cair em um puro formalismo jurídico e desconhecer que, à margem destas normalizações formais, a ação da Administração se rege por fins teleológicos inescusáveis e por princípios indestrutíveis que regram sua conduta com tanto ou mais vigor que as disposições legais." 40

Colocada está, portanto, a concepção que entendemos ser a vigente no Estado contemporâneo do Princípio da Legalidade e do poder normativo da Administração Pública, que, por um lado, não limita os regulamentos à mera especificação de preceitos que já devem estar previamente fixados em lei, e, por outro, não os limita ou potencializa apenas pela Lei que estiverem regulamentando, mas sim pelo ordenamento jurídico hierarquicamente superior como um todo.

consubstancia-se, na verdade, em uma regra tanto para as relações entre o Estado e os particulares quanto nas relações juridicas intersubjetivas, entre particulares. O que o princípio constitucional está a garantir não é o antigo "reino da liberdade" mas, sim o Estado Democrático de Direito, que se opõe ao Estado de Polícia, ou do Arbítrio. No Estado Democrático de Direito, o poder do Estado está limitado pelo Direito; mas não só: o poder da vontade do particular, em suas relações com outros particulares, também o está. Limita-o não apenas a eventual norma imperativa, contida nas leis ordinárias, mas, sobretudo, os princípios constitucionais de solidariedade social e dignidade humana que se espraiam por todo o ordenamento civil, infra-constitucional. Evidentemente, permanecem espaços abertos de liberdade, mas esta liberdade (autonomia) é consentida e já não serve mais a definir o sistema de direito privado" (MORAES, Maria Celina Bodin. Constituição e Direito Civil: tendências, in Revista Direito, Estado e Sociedade, PUC-RJ, vol. 15, grifamos).

39 LARENZ, Karl. Derecho Justo, trad. Luís Diez-Picazo, Ed. Civitas, Madrid, 1985, pp. 168 a 171.

40 SESÍN, Domingo J. Administración Pública. Actividad Reglada, Discrecional e Técnica. Ed. Depalma, Buenos Aires, 1994, p. 10. 